\title{
Short term culture with cAMP modulators before vitrification significantly improve actin integrity in bovine oocytes
}

\author{
Clara Ana Santos Monteiro ${ }^{\mathrm{a}, \mathrm{d}}$, Gabriela Ramos Leal ${ }^{\mathrm{a}, \mathrm{d}}$, Helena Fabiana Reis de Almeida Saraiva ${ }^{\mathrm{a}}$, \\ Joaquim Mansano Garcia ${ }^{\mathrm{c}}$, Agostinho Jorge dos Reis Camargo ${ }^{\mathrm{b}}$, Raquel Varella Serapião ${ }^{\mathrm{b}}$, Luiz \\ Altamiro Garcia Nogueira ${ }^{a}$, André Luís Rios Rodrigues ${ }^{\mathrm{a}}$, Clara Slade Oliveira ${ }^{\mathrm{d}, *}$

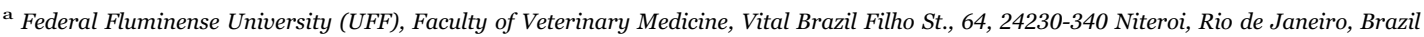 \\ ${ }^{\mathrm{b}}$ Agricultural Research Company of the Rio de Janeiro State (PESAGRO RIO), São Boa Ventura Av., 770, 24120-19 Fonseca, Niteroi, Rio de Janeiro, Brazil \\ ${ }^{\text {c }}$ São Paulo State University (UNESP), Prof. Paulo Donato Castellane Rd., S / n, 14884-900, Jaboticabal, São Paulo, Brazil \\ ${ }^{\mathrm{d}}$ Embrapa Dairy Cattle, Laboratory of Animal Reproduction, Santa Monica Experimental Field (LRA-CESM), Santa Monica Rd., 27640-000 Valença, Rio de \\ Janeiro, Brazil
}

\section{A R T I C L E I N F O}

\section{Keywords:}

Forskolin

IBMX

Vitrification

Pre-IVM

VG oocytes

\begin{abstract}
A B S T R A C T
Oocyte cryopreservation is a strategic tool for assisted reproduction, but has limited use due to the complex cellular structure of oocytes, which leads to sub-optimal survival rates. In this study, we used the SPOM in vitro maturation system, which is based on supplementation of cAMP modulators in order to extend meiotic arrest and improve oocyte maturation. cAMP modulators (Forskolin and IBMX) were administered in a short term culture (STC) before or after vitrification, followed by an extended maturation with cilostamide. We hypothesized that a STC with cAMP modulators would improve immature oocyte health and enhance cryotolerance. We found vitrification caused oocyte damage in a great extent, impairing nuclear maturation rates in all vitrified groups (Percentage of matured oocytes: CONT FRESH $77.8^{\mathrm{c}}$; CONT VIT $31.4^{\mathrm{ab}}$; STC/VIT $39.5^{\mathrm{b}}$; VIT/STC $18.6^{\mathrm{a}}$ ). Vitrification also promoted degradation of cytoskeletal actin filaments (Percentage of Injured oocytes: CONT FRESH $0.0^{\mathrm{a}}$; CONT VIT 50.0 ; STC/VIT $39.7^{\mathrm{b}}$; VIT/STC $74.0^{\mathrm{c}}$ ), and increased calcium release (Calcein-AM mean \pm SD: IMMATURE $1.0 \pm 0.49$; VIT $1.76 \pm 1.13$; STC $1.38 \pm 0.95$; STC/VIT $1.58 \pm$ 0.99). However, STC seemed to attenuate negative effects of vitrification, since oocytes subjected to STC prior to vitrification presented predominance of polymerized actin filaments (Percentage of Intact oocytes). Unfortunately, embryo cleavage rate (SPOM 73.66 a ; STC/VIT 7.91 ${ }^{\mathrm{b}}$; VIT/STC $4.62^{\mathrm{b}}$ ) and blastocyst development rate (SPOM 25.14 ; STC/VIT 1.34 ; VIT/STC $0.00^{\mathrm{b}}$ ) was impaired in vitrified groups, regardless STC treatment. In conclusion, STC with cAMP modulators, Forskolin and IBMX, decreases cytoskeleton actin filaments injuries caused by oocyte vitrification, which may consequently increase oocyte viability. Our results suggest STC should be considered and improved for immature oocyte vitrification systems.
\end{abstract}

\section{Introduction}

Oocyte cryopreservation is considered a strategic tool for embryo in vitro production (IVP) in livestock, facilitating transport and commercialization of these gametes. It is also a technic often applied before cancer treatment, in order to preserve the patient's capability of conceiving (Mahajan, 2015). In addition, genetic conservation and preservation of endangered-species can also be achieved by oocyte cryopreservation (Andrabi and Maxwell, 2007). However, reduced survival of frozen oocytes results in low rates of embryo development and pregnancy (Vajta et al., 1998; Lane and Gardner, 2001), limiting its use in routine.
Compared to blastocysts, oocytes are particularly challenging to cryopreserve due to their large cell size (Chen et al., 2003) and plasma membrane singularities (Jin et al., 2011). Also, oocytes have a higher lipid content compared to blastocysts (Ruffing et al., 1993). Those characteristics hinder the penetration of cryoprotectants, increasing oocyte sensitivity to cryopreservation process.

As a result of the reduced cryotolerance, oocytes display morphological and physiological damages after cryopreservation, mostly involved with cytoplasmic membrane, cytoskeleton and intercellular junctions (Vajta, 2000). In addition, hardening of the zona pellucida, due to premature exocytosis of cortical granules, can impair fertilization (Mavrides and Morroll, 2005), resulting in considerable decrease

\footnotetext{
* Corresponding author.

E-mail address: clara.oliveira@embrapa.br (C.S. Oliveira).
} 
in embryonic development potential. In this context, improvement of oocyte quality may be a valuable strategy to enhance its viability after cryopreservation.

Recent studies demonstrated that short term culture (STC) with cyclic adenosine $3^{\prime}, 5^{\prime}$-monophosphate (cAMP) modulators, such as Forskolin (FK) and 3-Isobutyl-1-methylxanthine (IBMX), prior to in vitro maturation (IVM) promotes a significant improve in oocyte quality, resulting in benefits to embryo development (Rose et al., 2013; Richani et al., 2014; Appeltant et al., 2015; Ulloa et al., 2015). Those studies aimed to prolong the meiotic arrest in an attempt to offer to the oocytes in vitro conditions more similar to those found in vivo, thus producing structures with greater development competence.

cAMP is an important molecule in signal transduction within the cell, functioning as a second cell messenger of gonadotrophin stimulation. It is known that its levels are controlled through modulation of its synthesis by adenylyl cyclase (AC) enzyme at the oocyte (Kuyt et al., 1988) and the granulosa cells (Thomas et al., 2004), and by degradation, through the cyclic nucleotide phosphodiesterase (PDE) enzymes within the cumulus-oocyte complexes (COCs) (Sirard and Bilodeau, 1990). High levels of cAMP keep the meiosis block suppressing activation of maturation promoting factor (MPF), and low levels leads to MPF activation, resulting in germinal vesicle breakdown and resumption of meiosis (Mermillod et al., 2000; Bilodeau-Goeseels, 2011).

In addition, STC with cAMP modulators increases the extent of communication between the oocyte and cumulus cells by maintaining the integrity of gap junctions (Albuz et al., 2010). Communication between oocyte and cumulus cells provides essential metabolic support for the oocyte growth, maturation and embryo development after fertilization (Li and Albertini, 2013), besides it is related with the regulation of anti-oxidation and redox potential (Combelles et al., 2009; Li et al., 2011).

The STC with cAMP presents encouraging results regarding oocyte quality, therefore we believe this system could be beneficial to vitrified oocytes. In the present study, we analyzed viability parameters such as nuclear maturation, cytoskeleton integrity and gap junctional activity, since the disruption of those are often side effects of vitrification procedure, besides cleavage and embryo development. Therefore, the aim of this study was to use the STC with cAMP modulators in order to enhance oocyte cryotolerance.

\section{Material methods}

\subsection{Reagents}

All chemicals used in this study were purchased from SigmaAldrich Chemical Co. unless otherwise stated.

\subsection{Experimental design}

The main purpose of this study was to evaluate the effect of STC with cAMP modulators before and after vitrification/warming (VIT) on oocyte viability parameters (i) nuclear maturation, (ii) actin filaments integrity, (iii) gap junctions activity, besides embryo in vitro production. For that, experiments were designed in two assays.

In assay 1 we tested the effect of the simulated physiological oocyte maturation (SPOM), a two-step IVM system comprising of (i) a STC with cAMP modulators (originally named as pre-IVM) +(ii) extended IVM (Albuz et al., 2010). Step (i) STC was employed before (STC/VIT group) and after (VIT/STC group) vitrification of immature oocytes. After maturation period, oocytes were fixed for nuclear maturation and actin filaments analyses. For controls of those analysis immature oocytes were VIT (CONT VIT group) our not (CONT FRESH group), than subjected to IVM in standard TCM based medium. Gap juntions activity was assessed right after VIT (VIT group), STC followed by vitrification/warming (STC/VIT group) and STC alone (STC group).
Immature oocytes were controls for that analysis.

In addition, assay 2 tested in vitro embryo production within groups: fresh oocytes matured in SPOM system (SPOM group), STC/ VIT group and VIT/STC group.

\subsection{Oocyte collection and selection}

Ovaries were collected at local abattoir and processes within two hours after killing. The ovaries were washed in saline at $35-37^{\circ} \mathrm{C}$ and follicles measuring $3-8 \mathrm{~mm}$ in diameter were aspired using an $18 \mathrm{G}$ needle coupled to a $20 \mathrm{ml}$ syringe. COCs having at least three cumulus cells layers and homogeneous cytoplasm were selected under a stereomicroscope and washed in TCM-199 buffered with HEPES (Gibco BRL, Grand Island, NY) supplemented with $1.0 \mathrm{mM}$ sodium pyruvate (Gibco BRL, Grand Island, NY) and 100 UI penicillin and $0.1 \mathrm{mg} / \mathrm{ml}$ streptomycin.

\subsection{Oocyte vitrification and warming}

Vitrification media (BM: base media; VT1: vitrification solution one, VT2: vitrification solution two) was prepared according to (Vajta et al., 1998), with minor modifications. First, oocytes were washed in BM (TCM-199 buffered with HEPES (Gibco BRL, Grand Island, NY) supplemented with $1.0 \mathrm{mM}$ sodium pyruvate (Gibco BRL, Grand Island, NY), 100UI penicillin, $0.1 \mathrm{mg} / \mathrm{ml}$ streptomycin, and $20 \%$ fetal calf serum (FCS)). Then they went through two step vitrification media (VT1, VT2) containing increasing concentrations of cryoprotectant, dimetilsulfoxide (DMSO) and ethylene glycol (EG). VT1 consisted in BM with 7.5\% DMSO and 7.5\% EG, wherein the oocytes remained for three minutes. VT2 consisted in BM with $16.5 \%$ DMSO and $16.5 \%$ EG, in which each oocyte remained 30-40 s before being deposited on the vitrification device (WTA ${ }^{\oplus}$, Watanabe Applied Technology Ltd, Brazil) and dipped into liquid nitrogen.

For warming, oocytes were plunged in BM with $0.5 \mathrm{M}$ Sucrose solution for five minutes, and then were washed for one minute in BM, to remove the sucrose.

\section{5. $I V M$}

In VIT group IVM was performed in TCM-199 supplemented with $0.2 \mathrm{mg} / \mathrm{ml} \mathrm{BSA}, 1.0 \mathrm{mM}$ sodium pyruvate (Gibco BRL, Grand Island, $\mathrm{NY}$ ), $0.5 \mathrm{mg} / \mathrm{ml}$ FSH (Folltropin ${ }^{\mathrm{TM}}$, Bioniche Animal Health, Belleville, ON, Canada), $10 \mathrm{IU} / \mathrm{ml}$ of hCG, $1 \mu \mathrm{g} / \mathrm{ml} \beta$-estradiol, $12.5 \mu \mathrm{g} / \mathrm{ml}$ recombinant human insulin, $6.875 \mu \mathrm{g} / \mathrm{ml}$ human transferrin (substantially iron-free), and $6.25 \mathrm{ng} / \mathrm{ml}$ sodium selenite (ITS) and $100 \mathrm{UI}$ penicillin, $0,1 \mathrm{mg} / \mathrm{ml}$ streptomycin for $24 \mathrm{~h}$ at $38.5{ }^{\circ} \mathrm{C}, 5 \% \mathrm{CO} 2$ in atmospheric air and maximum humidity.

In assays 1 and 2, the SPOM IVM protocol was adapted from Albuz et al. (2010). The step 1 of SPOM system (STC), was carried out in $100 \mu \mathrm{l} / 10-20$ COCs in TCM-199 buffered with HEPES and supplemented with $0.4 \mathrm{mg} / \mathrm{ml} \mathrm{BSA}, 1.0 \mathrm{mM}$ sodium pyruvate (Gibco BRL, Grand Island, NY, USA), $12.5 \mu \mathrm{g} / \mathrm{ml}$ recombinant human insulin, $6.875 \mu \mathrm{g} / \mathrm{ml}$ human transferrin (substantially iron-free), and $6.25 \mathrm{ng} /$ $\mathrm{ml}$ sodium selenite (ITS) and 100 UI penicillin, $0,1 \mathrm{mg} / \mathrm{ml}$ streptomycin, $100 \mu \mathrm{M}$ FK and $500 \mu \mathrm{M}$ IBMX, and kept for $2 \mathrm{~h}$ at $38.5^{\circ} \mathrm{C}$. Then SPOM- extended IVM was performed in $500 \mu$ l of IVM medium composed of TCM-199 supplemented with $0.2 \mathrm{mg} / \mathrm{ml} \mathrm{BSA}, 1.0 \mathrm{mM}$ sodium pyruvate (Gibco BRL, Grand Island, NY), $0.5 \mathrm{mg} / \mathrm{ml} \mathrm{FSH}$ (Folltropin ${ }^{\mathrm{TM}}$, Bioniche Animal Health, Belleville, ON, Canada), $10 \mathrm{IU} /$ $\mathrm{ml} \mathrm{hCG}, 1 \mu \mathrm{g} / \mathrm{ml} \beta$-estradiol, $12.5 \mu \mathrm{g} / \mathrm{ml}$ recombinant human insulin, $6.875 \mu \mathrm{g} / \mathrm{ml}$ human transferrin (substantially iron-free), and $6.25 \mathrm{ng} /$ $\mathrm{ml}$ sodium selenite (ITS) and 100 UI penicillin, $0,1 \mathrm{mg} / \mathrm{ml}$ streptomycin, with $20 \mu \mathrm{M}$ cilostamide, and cultured for $28 \mathrm{~h}$ at $38.5{ }^{\circ} \mathrm{C}, 5 \% \mathrm{CO} 2$ in atmospheric air and maximum humidity. 


\section{6. $I V F / I V C$}

In assay 2, groups (SPOM, STC/VIT and VIT/STC) were subjected to IVF and IVC. Briefly, after SPOM IVM, groups of 10-20 oocytes were washed twice and transferred to $30 \mu \mathrm{l}$ drops of commercial IVF medium (Bioklone ${ }^{\circledR}$ Reprodução Animal, São Paulo, Brazil) covered with sterile mineral oil. For IVF frozen straws of conventional semen of the same bull were used. Each straw containing 20 million spermatozoa was centrifuged on a discontinuous 45/90 Percoll gradient for $7 \mathrm{~min}$ at $3600 \mathrm{~g}$. The $80 \mu \mathrm{l}$ pellet was ressuspended in $1.0 \mathrm{ml}$ IVF medium and again centrifuged for $5 \mathrm{~min}$ at $520 \mathrm{~g}$. After centrifugation, $50 \mu \mathrm{l}$ of the medium containing the pellet was collected from the bottom of the tube and homogenized in a conic tube. The final suspension was divided among ten drops containing one to ten oocytes or five drops containing ten to 20 oocytes, in a final concentration of $5 \times 10^{3}$ spermatozoa for each oocyte. The plates were incubated at $38.5^{\circ} \mathrm{C}$ for $20 \mathrm{~h}$ in an atmosphere of $5 \% \mathrm{CO} 2$ in air under saturated humidity. After IVF, presumptive zygotes were partially denuded of cumulus cells by vigorous pipetting and groups of 15-20 presumptive zygotes were cultured in $100 \mu \mathrm{l}$ drops of commercial SOF medium (Bioklone ${ }^{\circledR}$ Reprodução Animal, São Paulo, Brazil) covered with sterile mineral oil at $38.5{ }^{\circ} \mathrm{C}$ in an atmosphere of $5 \% \mathrm{CO} 2$ in air under saturated humidity for seven days. Cleavage rate was assessed $48-72 \mathrm{~h}$ after IVF and blastocyst rate at $\mathrm{d} 7$ of development.

\subsection{Nuclear maturation}

For analysis of nuclear maturation, oocytes were denuded in $2 \mathrm{mg} /$ $\mathrm{ml}$ hyaluronidase solution, fixed in $4 \%$ paraformaldehyde (PFA) solution for $30-40 \mathrm{~min}$, and stored at $4{ }^{\circ} \mathrm{C}$. At the time of analysis oocytes were stained with Hoechst 33342 and evaluated in a fluorescence microscope (Olympus IX-70, Tokyo, Japan) at a wavelength between $340-380 \mathrm{~nm}$, for nuclear configuration in germinal vesicle (GV), metaphase I (M I) and metaphase II (M II), to obtain the rate of matured (MII) oocytes in each experimental group. Immature oocytes $(n=15)$ were stained side by side to guarantee the reliability of the assay, and displayed $93.3 \% \mathrm{GV}$ oocytes.

\subsection{Actin integrity}

Cytoskeletal integrity analysis was performed by the evaluation of actin filaments. Denuded and PFA-fixed oocytes were stained with Phalloidin (Phalloidin Atto-532; 1:30 in concentration) for $30 \mathrm{~min}$. Oocytes were evaluated under a fluorescence microscope (Olympus IX70, Tokyo, Japan) with a wavelength between $568-592 \mathrm{~nm}$. Images of each structure were recorded using AxioCam camera and 4.7.1 AxioVision software (Carl Zeiss, Jena, Germany). In our assay, Phalloidin staining pattern was read as intact, when oocyte was stained, or injured, when oocyte was not stained, as Phalloidin stain binds strongly to polymerized form of actin, F-actin. Immature oocytes $(n=9)$ were stained before any treatment as a control of the staining. Those displayed $100.0 \%$ of the intact pattern (stained).

\subsection{Gap junctional activity}

Gap Junctional activity was estimated by transfer of substances between the cumulus cells and oocyte, using a calcein-AM staining protocol (Thomas et al., 2004). Calcein-AM passively diffuses into the cells and when the AM portion is cleaved releasing the calcium binding site of calcein, it fluoresces. The calcein, being negatively charged, does not leave the cell by plasma membrane, only by gap junctions.

To perform this evaluation, the oocytes were transferred to medium containing calcein AM (1 mM) in the absence of phenol red and proteins for $15 \mathrm{~min}$. Then, structures were transferred to calcein AM free medium for $25 \mathrm{~min}$, and washed three times. After, COCs were denuded and oocytes were evaluated in a fluorescence microscope
(Olympus IX-70, Tokyo, Japan) in a 496-516 nm wavelength. Images of each structure were recorded using AxioCam camera and 4.7.1 AxioVision software (Carl Zeiss, Jena, Germany) and measured for fluorescent intensity by ImageJ software. The mean fluorescence intensity of each oocyte was recorded, and results were normalized by the mean values of IMMATURE group. The final data refers to relative florescence intensity, reflecting gap activity in comparison with immature untreated oocytes, considered the expected pattern for this analysis. A second analysis was performed wherein the structures have been divided according to the staining patterns observed (Low, Middle and High intensity).

\subsection{Statistical analyses}

Rates of matured oocytes (MII), cleavage and blastocyst were evaluated by chi-square test $(\chi 2)$. As for the gap junctions activity, the results were submitted to nonparametric Kruskal-Wallis test and Dunn post-test. The percentages of staining patterns and integrity of the cytoskeleton (actin) were compared between groups using Fisher's exact test. Analyses were performed in GraphPad INSTAT, at the significance level of $5 \%$.

\section{Results}

\subsection{Assay 1: effect of STC with cAMP modulators before and after vitrification on oocyte viability}

Regarding nuclear maturation as viability parameter, 270 viable oocytes were obtained in three replicates and distributed among groups (CONT FRESH $\mathrm{n}=54$; CONT VIT $\mathrm{n}=70$; STC/VIT $\mathrm{n}=76$; VIT/STC $\mathrm{n}=70$ ). We observed that all vitrified groups presented lower MII rate percentages compared to CONT FRSH group, demonstrating the negative effect of vitrification on meiotic progression. Among vitrified groups CONT VIT did not differ from the other groups $(\mathrm{P}>0.05)$, as demonstrated in Fig. 1A.

As for actin filaments integrity analysis, 238 viable oocytes were obtained in two replicates and distributed among groups (CONT FRESH n=47; CONT VIT n=68; STC/VIT n=73; VIT/STC n=50). We observed that all vitrified groups presented lower stained (intact) oocytes pattern compared to CONT FRESH group, demonstrating the negative effect of vitrification on actin filaments integrity. Among vitrified groups, the one submitted to STC before vitrification was the only one whose intact pattern was higher than non-stained (injured) pattern (Fig. 1B and C), suggesting that STC has positive effects in protecting actin filaments integrity from the negative effects of vitrification procedure.

In the gap juntions activity analyses, 404 viable oocytes were obtained in three replicates and distributed among groups (groups IMMATURE $\mathrm{n}=89$; VIT $\mathrm{n}=122 ;$ STC $\mathrm{n}=89 ;$ STC/VIT $\mathrm{n}=104)$. We observed an increase in fluorescence intensity in all experimental groups compared to IMMATURE (IMMATURE $1.0 \pm 0.49$; VIT 1.76 \pm 1.13 ; STC $1.38 \pm 0.95$; STC/VIT $1.58 \pm 0.99$; Means \pm SD; $\mathrm{P}<0.05$ ), as demonstrated in Fig. 1D and F. We also evaluated the staining pattern of each oocyte (High/Middle/Low). In this analysis, IMMATURE group presented similar percentages of Middle and Low patterns. Taken IMMATURE group as the expected pattern, we observed that VIT group displayed a different pattern $(\mathrm{p}<0.05)$, suggesting a detrimental effect when vitrification is applied. Witch appeared to be attenuated when STC is performed before vitrification, since STC/VIT group and IMMATURE group presented similar pattern $(\mathrm{p}>0.05)$, as demonstrated in Fig. 1E.

\subsection{Assay 2: Embryo production}

For analysis, 827 viable oocytes were obtained in five replicates and distributed in three experimental groups (groups SPOM: n=186; STC/ 
A

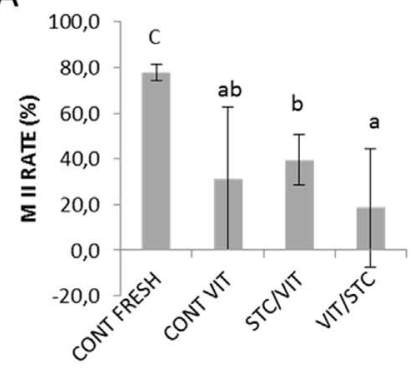

D

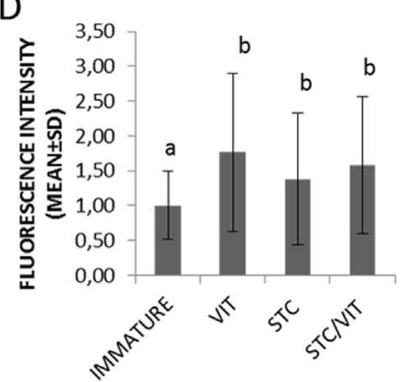

B

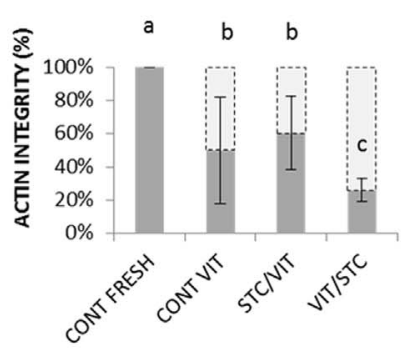

$\mathrm{E} \quad \because \% \mathrm{LOW} \backsim \mathrm{MIDDLE} \| \mathrm{HIGH}$

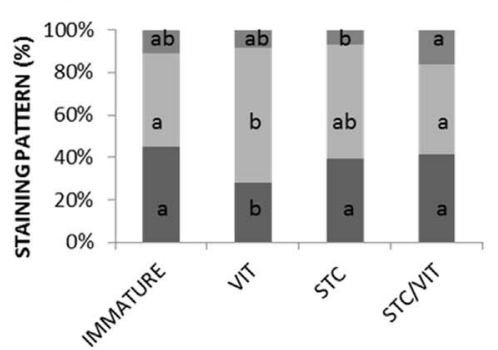

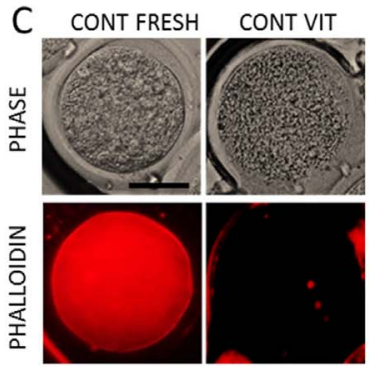

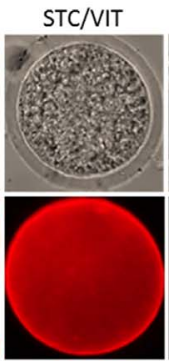

$\mathrm{VIT} / \mathrm{STC}$

$\mathrm{F}$

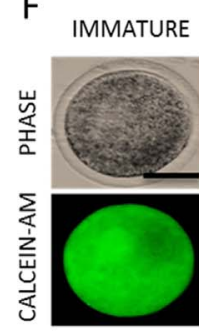

VIT

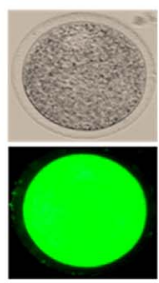

STC

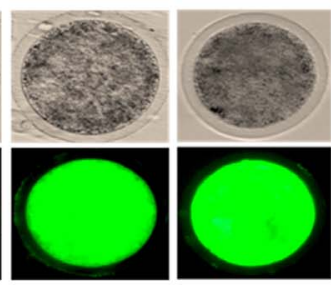

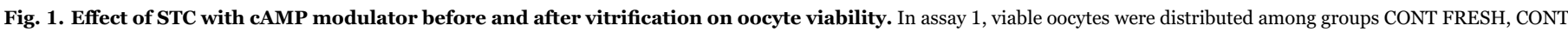

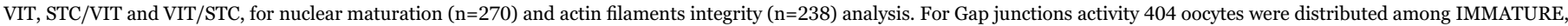

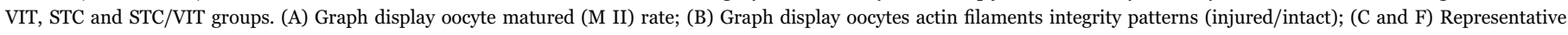

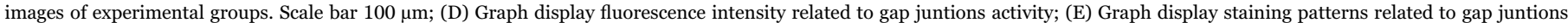
activity. Graphs A and B display bars indicating the variation associated to replicates. Superscript letters denote statistical difference (p < 0.05) between groups.

Table 1

Embryo in vitro production of vitrified-warmed oocytes before and after STC with cAMP modulators.

\begin{tabular}{llllll}
\hline Groups & $\begin{array}{l}\text { N viable } \\
\text { oocytes }\end{array}$ & Cleavage rate & \multicolumn{2}{l}{ Blastocyst rate } \\
\cline { 4 - 6 } \cline { 4 - 5 } & & n (\%) & $\mathbf{N}$ & $\%$ (cleavage) & $\begin{array}{l}\text { \% (viable } \\
\text { oocytes) }\end{array}$ \\
\hline SPOM & 186 & $137(73.66)^{\mathrm{a}}$ & 43 & $34.66^{\mathrm{a}}$ & $25.14^{\mathrm{a}}$ \\
STC/VIT & 316 & $25(7.91)^{\mathrm{b}}$ & 3 & $10.71^{\mathrm{ab}}$ & $1.34^{\mathrm{b}}$ \\
VIT/STC & 325 & $15(4.62)^{\mathrm{b}}$ & 0 & $0.00^{\mathrm{b}}$ & $0.00^{\mathrm{b}}$ \\
\hline
\end{tabular}

For analysis, 827 viable oocytes were obtained in five replicates and distributed in three experimental groups (SPOM, STC/VIT and VIT/STC). Table display cleavage and blastocyst rate between groups. Superscript letters denote statistical difference $(\mathrm{p}<0.05$, chi-square test- $\chi 2$ ) between groups.

VIT: $n=316$; and VIT/STC: $n=325$ ), before IVF and IVC. We observed that vitrified groups display a significant reduction in cleavage rate (SPOM: $73.66^{\mathrm{a}}$; STC/VIT: $7.91^{\mathrm{b}}$; and VIT/STC: $4.62^{\mathrm{b}}$ ), as presented en Table 1. As for blastocyst production, none of the 325 viable oocytes of the VIT/STC group develops into a blastocyst stage. So taken in consideration the cleaved zygotes, only the VIT/STC differ from control group (SPOM: $34.66^{\mathrm{a}}$; STC/VIT: $10.71^{\mathrm{ab}}$; and VIT/STC: $0.00^{\mathrm{b}}$ ), and considering the viable oocytes submitted to treatments both vitrified groups had lower blastocyst rate (SPOM: $25.14^{\mathrm{a}}$; STC/VIT: $1.34^{\mathrm{b}}$; and VIT/STC: $0.00^{\mathrm{b}}$ ).

\section{Discussion}

The main findings of this study were that: (i) short term culture with cAMP modulators significantly improves cytoskeletal actin filaments integrity of vitrified-warmed bovine oocytes; (ii) vitrification, as well as STC, caused an increase in gap junctions activity, but immature vitrified oocytes differ from the expected staining pattern, effect that was attenuated when the STC was performed prior to vitrification; and (iii) vitrification significantly impaired cleavage and embryo production, regardless the STC treatment.

Vitrified oocytes viability is often assessed by morphological evaluation and fertilization competence. Such parameters provide limited information about the cryoinjury in oocytes undergoing vitrification (Coticchio et al., 2005, 2007), therefore little is known about how to prevent or reverse these effects. Thus, the present study evaluated different cellular parameters such as nuclear maturation progression, cytoskeletal actin filaments integrity and gap junctions activity besides the cleavage and embryo production in order to compare the effect of a STC with cAMP modulators in vitrified oocytes viability.

Our results demonstrate a decrease in matured oocytes rate in vitrified groups as a result of a deleterious effect of vitrification on meiosis resumption competence that leads to a significant decrease in viability of cryopreserved oocytes (Carroll et al., 1990; Mavrides and Morroll, 2005). Still, all vitrified groups presented lower percentage of oocytes displaying intact cytoskeleton. Phalloidin stain has a strong affinity with polymerized actin (F-actin), so the injured pattern (nonstained) results from the actin filaments depolymerization, possibly caused by vitrification process. Thereby confirming the deleterious effect of vitrification process on cytoskeleton integrity (Prentice et al., 2011).

In the present study, our approach was to vitrify immature oocytes, in order to overcome the disruption of the meiotic spindle by depolymerization of microtubules that occurs when MII oocytes are vitrified (Men et al., 2002; Rojas et al., 2004; Prentice et al., 2011). However, as our results showed, even with the vitrification of immature oocytes nuclear maturation was impaired. This happens because immature oocytes presents lower permeability of the plasma membrane to cryoprotectants (Agca et al., 1998), and the damage to the cytoskeleton after rewarming affects the segregation of chromosomes in meiosis I phase (Saragusty and Arav, 2011) - a cytoskeleton dependent event ( $\mathrm{Li}$ and Albertini, 2013). Together, those results demonstrate the importance of cytoskeleton on nuclear maturation events, and also demonstrates the impact of vitrification procedure.

Regarding the analysis of nuclear maturation, among vitrified groups, STC before (STC/VIT) or after (VIT/STC) the vitrification had a similar result to the control group (CONT VIT). However, we observed a high deviation between repetitions in the CONT VIT $(31.4 \%$ $\pm 31.2)$ and VIT/STC $(18.6 \% \pm 25.9)$ groups, compared to that found in 
the STC/VIT group $(39.5 \% \pm 11.1)$. This finding may indicate that treatment with STC prior to vitrification has a more stable outcome with regard to meiotic progression. Moreover, our results demonstrated that the STC with cAMP modulators (the first step of SPOM system) applied before vitrification improved oocyte cryotolerance, as indicated by an increased in cytoskeletal actin filaments integrity, which has an important role in meiosis progression.

Several studies have demonstrated that higher cAMP levels before IVM improves oocyte competence and subsequent embryonic development of human (Shu et al., 2008; Zeng et al., 2013), murine (Albuz et al., 2010; Zeng et al., 2013), bovine (Luciano et al., 1999; Guixue et al., 2001; Albuz et al., 2010), ovine (Rose et al., 2013) and porcine (Funahashi et al., 1997) IVM oocytes.

Previous studies have hypothesized that a culture before IVM inhibiting the meiotic progression with Roscovitin, might offer to oocytes conditions to acquire greater developmental conditions after vitrification-warming, but these pretreatment did not return beneficial effects on vitrified oocyte viability (Albarracín et al., 2005; Diez et al., 2005). It seems like Roscovitin might induce significant changes, such as disruption of the integrity of the surrounding cumulus cells, swelling of the mitochondrial crista and degeneration of the cortical granules (Lonergan et al., 2003). Therefore, it is crucial to identify substances that can modulate cAMP levels without side effects on oocytes. In supplementary data we demonstrated that those cAMP modulators, FK and IBMX, do not cause detrimental effect on oocytes.

A recent study has showed that the addition of FSK or IBMX to the IVM medium tended to improve the developmental competence after IVF of vitrified-warmed GV oocytes (Ezoe et al., 2015). In our study, a STC with FK and IBMX after oocytes vitrification-warming did not return benefits regarding the viability parameters assessed - only when STC was performed prior to vitrification/warming benefits were observed.

It is known that cryopreservation causes damage to gap junctions, interrupting communication between the oocyte and cumulus cells (Diez et al., 2005). Since STC with cAMP modulators have been proven to improve gap junctions activity (Albuz et al., 2010), gap junctions were also a parameter assessed in this study. Unexpectedly, vitrification procedure itself also increased gap junctional activity, as was found for STC procedure. However, concerning staining pattern analysis, our results showed only vitrified group was different from immature oocytes taken as expected pattern, suggesting vitrified and STC groups could have gap activity affected by different ways.

It has been demonstrated that matured oocytes exposed to cryoprotectants and temperature drop during cryopreservation exhibited a transient increase in intracellular free calcium (Mattioli et al., 2003), which results in blocking the sperm entry by early release of cortical granules, a calcium-dependent event (Kline and Kline, 1992), thereby reducing the competence for development of oocytes. Besides gap junctional activity, calcein AM assay, used in this study, provides an intracellular free calcium estimative, so it is possible that this increase of calcium during the vitrification interfered with measurements of cumulus-oocyte communication. Additionally previous studies have reported that a transient increase of free calcium it's an environmental change that may lead in spontaneous activation (SA), which is an incomplete and abortive activation that severely damage oocyte developmental competence (Cui et al., 2013).

Regarding the increase in fluorescence intensity due to STC, it is likely to be involved with the calcium role in oocyte maturation (Homa, 1995; He et al., 1997). In many cell types, the activation of hormones and growth factors receptors causes an increase in intracellular free calcium (reviewed by (Williamson and Monck, 1990)). A calcium rise was described in bovine COCs after their exposure to IVM hormones (Silvestre et al., 2012). In vivo, the LH surge causes a rise in calcium free that starts in cumulus cells (Gudermann et al., 1992; Mattioli et al., 1998). Stimulation of LHRs leads to activation of two intracellular signaling pathways. The first refers to the activation of adenylyl cyclase, resulting in a transient increase in cAMP (Eppig and Downs, 1984). The second involves the stimulation of phospholipase $\mathrm{C}$ and production of inositol phosphates, most specifically 1,4,5-inositol triphosphate (IP3), which leads to elevation in calcium levels (Gudermann et al., 1992), resulting in a decrease in cAMP through calcium-activated phosphodiesterases (Bornslaeger et al., 1984). The calcium is provided, besides the intracellular stocks, from cumulus cells, throw gap junctions (Carroll and Swann, 1992), throw plasma membrane channels (Murnane and DeFelice, 1993; Tosti et al., 2000). So, the increase in cAMP mediated by Forskolin stimulation may activate the downstream degradation pathway, elevating both PDE C and calcium, but the IBMX inhibition let calcium free to bind calcein. Still, STC prolongs gap junctions communications (Albuz et al., 2010), explaining an important source of calcium and its increased levels.

Additionally, our data regarding the embryo production shows that vitrification significantly impaired cleavage and development of blastocysts, regardless the STC treatment. Curiously, the group submitted to STC before vitrification (STC/VIT) display similar cleavage rate compared to control group ( $\mathrm{p}=0.0549)$, however we believe that it is a really small probability of those groups to be similar, which may indicate a tendency of impaired embryo development showed in this group. As that group presents a small number of cleaved structures, this tendency it is not evident in that experiment. Results also demonstrate that, regarding the blastocyst rate (considering viable oocytes submitted to treatments), the vitrified groups are similar ( $\mathrm{p}=0.1192$ ). Although mathematically the probability to form zero or three blastocyst from 325/316 viable oocytes (VIT/STC and STC/VIT groups, respectively) are the same, considering this large amount of 5 repetitions with more than 600 biological structures, only the STC/VIT group was able to give conditions to develop blastocysts.

It is noteworthy that if only embryo production experiments were taken, the STC before vitrification of immature oocytes would not be considered in cryopreservation programs. However, in the present study we also consider oocyte quality parameters after treatment, which showed benefits on maturation. Therefore, we can conclude that STC with cAMP modulators, Forskolin and IBMX, decreases cytoskeleton injuries caused by oocyte vitrification, that might increase oocyte viability and meiosis resumption, however we suggest that further studies taken into consideration further improvements on that system, favoring embryo development.

\section{Conflict of interest statement}

All authors declare that this manuscript has not been published or simultaneously submitted for publication elsewhere. Authors also declare that this scientific work was conducted following the ethical guidelines of research and there is no conflict of interest.

Authors declare that this scientific work was conducted following the ethical guidelines of research and there is no conflict of interest.

\section{Acknowledgements}

This study was supported by Foundation for Research of the State of Rio de Janeiro (FAPERJ) and scholarship granted by the Higher Education Personnel Improvement Coordination (CAPES).

\section{Appendix A. Supplementary material}

Supplementary data associated with this article can be found in the online version at http://dx.doi.org/10.1016/j.livsci.2017.01.013.

\section{References}

Agca, Y., Liu, J., Peter, A.T., Critser, E.S., Critser, J.K., 1998. Effect of developmental stage on bovine oocyte plasma membrane water and cryoprotectant permeability characteristics. Mol. Reprod. Dev. 49, 408-415. 
Albarracín, J.L., Morató, R., Izquierdo, D., Mogas, T., 2005. Vitrification of calf oocytes: effects of maturation stage and prematuration treatment on the nuclear and cytoskeletal components of oocytes and their subsequent development. Mol. Reprod. Dev. 72, 239-249.

Albuz, F.K., Sasseville, M., Lane, M., Armstrong, D.T., Thompson, J.G., Gilchrist, R.B., 2010. Simulated physiological oocyte maturation (SPOM): a novel in vitro maturation system that substantially improves embryo yield and pregnancy outcomes. Hum. Reprod. 25, 2999-3011.

Andrabi, S.M., Maxwell, W.M., 2007. A review on reproductive biotechnologies for conservation of endangered mammalian species. Anim. Reprod. Sci. 99, 223-243.

Appeltant, R., Beek, J., Vandenberghe, L., Maes, D., Van Soom, A., 2015. Increasing the cAMP concentration during in vitro maturation of pig oocytes improves cumulus maturation and subsequent fertilization in vitro. Theriogenology 83, 344-352.

Bilodeau-Goeseels, S., 2011. Cows are not mice: the role of cyclic AMP, phosphodiesterases, and adenosine monophosphate-activated protein kinase in the maintenance of meiotic arrest in bovine oocytes. Mol. Reprod. Dev. 78, 734-743.

Bornslaeger, E.A., Wilde, M.W., Schultz, R.M., 1984. Regulation of mouse oocyte maturation: involvement of cyclic AMP phosphodiesterase and calmodulin. Dev. Biol. 105, 488-499.

Carroll, J., Swann, K., 1992. Spontaneous cytosolic calcium oscillations driven by inositol trisphosphate occur during in vitro maturation of mouse oocytes. J. Biol. Chem. 267, 11196-11201.

Carroll, J., Depypere, H., Matthews, C.D., 1990. Freeze-thaw-induced changes of the zona pellucida explains decreased rates of fertilization in frozen-thawed mouse oocytes. J. Reprod. Fertil. 90, 547-553.

Chen, S.U., Lien, Y.R., Chao, K.H., Ho, H.N., Yang, Y.S., Lee, T.Y., 2003. Effects of cryopreservation on meiotic spindles of oocytes and its dynamics after thawing: clinical implications in oocyte freezing-a review article. Mol. Cell Endocrinol. 202, $101-107$.

Combelles, C.M., Gupta, S., Agarwal, A., 2009. Could oxidative stress influence the invitro maturation of oocytes? Reprod. Biomed. Online 18, 864-880.

Coticchio, G., Bonu, M.A., Bianchi, V., Flamigni, C., Borini, A., 2005. Criteria to assess human oocyte quality after cryopreservation. Reprod. Biomed. Online 11, 421-427.

Coticchio, G., Bonu, M.A., Sciajno, R., Sereni, E., Bianchi, V., Borini, A., 2007. Truths and myths of oocyte sensitivity to controlled rate freezing. Reprod. Biomed. Online 15, $24-30$.

Cui, W., Zhang, J., Zhang, C.X., Jiao, G.Z., Zhang, M., Wang, T.Y., Luo, M.J., Tan, J.H., 2013. Control of spontaneous activation of rat oocytes by regulating plasma membrane $\mathrm{Na}+/ \mathrm{Ca} 2+$ exchanger activities. Biol. Reprod. 88, 160.

Diez, C., Duque, P., Gómez, E., Hidalgo, C.O., Tamargo, C., Rodríguez, A., Fernández, L., de la Varga, S., Fernández, A., Facal, N., Carbajo, M., 2005. Bovine oocyte vitrification before or after meiotic arrest: effects on ultrastructure and developmental ability. Theriogenology 64, 317-333.

Eppig, J.J., Downs, S.M., 1984. Chemical signals that regulate mammalian oocyte maturation. Biol. Reprod. 30, 1-11.

Ezoe, K., Yabuuchi, A., Tani, T., Mori, C., Miki, T., Takayama, Y., Beyhan, Z., Kato, Y Okuno, T., Kobayashi, T., Kato, K., 2015. Developmental Competence of vitrifiedwarmed bovine oocytes at the germinal-vesicle stage is improved by cyclic adenosine monophosphate modulators during in vitro maturation. PLoS One 10, e0126801.

Funahashi, H., Cantley, T.C., Day, B.N., 1997. Synchronization of meiosis in porcine oocytes by exposure to dibutyryl cyclic adenosine monophosphate improves developmental competence following in vitro fertilization. Biol. Reprod. 57, 49-53.

Gudermann, T., Birnbaumer, M., Birnbaumer, L., 1992. Evidence for dual coupling of the murine luteinizing hormone receptor to adenylyl cyclase and phosphoinositide breakdown and Ca2+ mobilization. Studies with the cloned murine luteinizing hormone receptor expressed in L cells. J. Biol. Chem. 267, 4479-4488.

Guixue, Z., Luciano, A.M., Coenen, K., Gandolfi, F., Sirard, M.A., 2001. The influence of cAMP before or during bovine oocyte maturation on embryonic developmental competence. Theriogenology 55, 1733-1743.

He, C.L., Damiani, P., Parys, J.B., Fissore, R.A., 1997. Calcium, calcium release receptors, and meiotic resumption in bovine oocytes. Biol. Reprod. 57, 1245-1255.

Homa, S.T., 1995. Calcium and meiotic maturation of the mammalian oocyte. Mol. Reprod. Dev. 40, 122-134.

Jin, B., Kawai, Y., Hara, T., Takeda, S., Seki, S., Nakata, Y., Matsukawa, K., Koshimoto, C., Kasai, M., Edashige, K., 2011. Pathway for the movement of water and cryoprotectants in bovine oocytes and embryos. Biol. Reprod. 85, 834-847.

Kline, D., Kline, J.T., 1992. Repetitive calcium transients and the role of calcium in exocytosis and cell cycle activation in the mouse egg. Dev. Biol. 149, 80-89.

Kuyt, J.R., Kruip, T.A., de Jong-Brink, M., 1988. Cytochemical localization of adenylate cyclase in bovine cumulus-oocyte complexes. Exp. Cell Res 174, 139-145.

Lane, M., Gardner, D.K., 2001. Vitrification of mouse oocytes using a nylon loop. Mol. Reprod. Dev. 58, 342-347.

Li, Q., Miao, D.Q., Zhou, P., Wu, Y.G., Gao, D., Wei, D.L., Cui, W., Tan, J.H., 2011. Glucose metabolism in mouse cumulus cells prevents oocyte aging by maintaining both energy supply and the intracellular redox potential. Biol. Reprod. 84, 1111-1118.
Li, R., Albertini, D.F., 2013. The road to maturation: somatic cell interaction and selforganization of the mammalian oocyte. Nat. Rev. Mol. Cell Biol. 14, 141-152.

Lonergan, P., Faerge, I., Hyttel, P.M., Boland, M., Fair, T., 2003. Ultrastructural modifications in bovine oocytes maintained in meiotic arrest in vitro using roscovitine or butyrolactone. Mol. Reprod. Dev. 64, 369-378.

Luciano, A.M., Pocar, P., Milanesi, E., Modina, S., Rieger, D., Lauria, A., Gandolfi, F., 1999. Effect of different levels of intracellular cAMP on the in vitro maturation of cattle oocytes and their subsequent development following in vitro fertilization. Mol. Reprod. Dev. 54, 86-91.

Mahajan, N., 2015. Fertility preservation in female cancer patients: an overview. J. Hum. Reprod. Sci. 8, 3-13.

Mattioli, M., Gioia, L., Barboni, B., 1998. Calcium elevation in sheep cumulus-oocyte complexes after luteinising hormone stimulation. Mol. Reprod. Dev. 50, 361-369.

Mattioli, M., Barboni, B., Gioia, L., Loi, P., Luisa, G., 2003. Cold-induced calcium elevation triggers DNA fragmentation in immature pig oocytes. Mol. Reprod. Dev. 65, 289-297.

Mavrides, A., Morroll, D., 2005. Bypassing the effect of zona pellucida changes on embryo formation following cryopreservation of bovine oocytes. Eur. J. Obstet. Gynecol. Reprod. Biol. 118, 66-70.

Men, H., Monson, R.L., Rutledge, J.J., 2002. Effect of meiotic stages and maturation protocols on bovine oocyte's resistance to cryopreservation. Theriogenology 57 , 1095-1103.

Mermillod, P., Tomanek, M., Marchal, R., Meijer, L., 2000. High developmental competence of cattle oocytes maintained at the germinal vesicle stage for 24 hours in culture by specific inhibition of MPF kinase activity. Mol. Reprod. Dev. 55, 89-95.

Murnane, J.M., DeFelice, L.J., 1993. Electrical maturation of the murine oocyte: an increase in calcium current coincides with acquisition of meiotic competence. Zygote $1,49-60$.

Prentice, J.R., Singh, J., Dochi, O., Anzar, M., 2011. Factors affecting nuclear maturation, cleavage and embryo development of vitrified bovine cumulus-oocyte complexes. Theriogenology $75,602-609$.

Richani, D., Wang, X., Zeng, H.T., Smitz, J., Thompson, J.G., Gilchrist, R.B., 2014. Prematuration with cAMP modulators in conjunction with EGF-like peptides during in vitro maturation enhances mouse oocyte developmental competence. Mol. Reprod. Dev. 81, 422-435.

Rojas, C., Palomo, M.J., Albarracín, J.L., Mogas, T., 2004. Vitrification of immature and in vitro matured pig oocytes: study of distribution of chromosomes, microtubules, and actin microfilaments. Cryobiology 49, 211-220.

Rose, R.D., Gilchrist, R.B., Kelly, J.M., Thompson, J.G., Sutton-McDowall, M.L., 2013. Regulation of sheep oocyte maturation using cAMP modulators. Theriogenology 79 $142-148$.

Ruffing, N.A., Steponkus, P.L., Pitt, R.E., Parks, J.E., 1993. Osmometric behavior, hydraulic conductivity, and incidence of intracellular ice formation in bovine oocytes at different developmental stages. Cryobiology 30, 562-580.

Saragusty, J., Arav, A., 2011. Current progress in oocyte and embryo cryopreservation by slow freezing and vitrification. Reproduction 141, 1-19.

Shu, Y.M., Zeng, H.T., Ren, Z., Zhuang, G.L., Liang, X.Y., Shen, H.W., Yao, S.Z., Ke, P.Q., Wang, N.N., 2008. Effects of cilostamide and forskolin on the meiotic resumption and embryonic development of immature human oocytes. Hum. Reprod. 23, 504-513.

Silvestre, F., Fissore, R.A., Tosti, E., Boni, R., 2012. [Ca2+]i rise at in vitro maturation in bovine cumulus-oocyte complexes. Mol. Reprod. Dev. 79, 369-379.

Sirard, M.A., Bilodeau, S., 1990. Granulosa cells inhibit the resumption of meiosis in bovine oocytes in vitro. Biol. Reprod. 43, 777-783.

Thomas, R.E., Armstrong, D.T., Gilchrist, R.B., 2004. Bovine cumulus cell-oocyte gap junctional communication during in vitro maturation in response to manipulation of cell-specific cyclic adenosine $3^{\prime}, 5^{\prime}$-monophosophate levels. Biol. Reprod. 70, $548-556$.

Tosti, E., Boni, R., Cuomo, A., 2000. Ca(2+) current activity decreases during meiotic progression in bovine oocytes. Am. J. Physiol. Cell Physiol. 279, C1795-1800.

Ulloa, S.M., Heinzmann, J., Herrmann, D., Timmermann, B., Baulain, U., Großfeld, R., Diederich, M., Lucas-Hahn, A., Niemann, H., 2015. Effects of different oocyte retrieval and in vitro maturation systems on bovine embryo development and quality. Zygote 23, 367-377.

Vajta, G., 2000. Vitrification of the oocytes and embryos of domestic animals. Anim. Reprod. Sci. 60-61, 357-364.

Vajta, G., Holm, P., Kuwayama, M., Booth, P.J., Jacobsen, H., Greve, T., Callesen, H., 1998. Open pulled straw (OPS) vitrification: a new way to reduce cryoinjuries of bovine ova and embryos. Mol. Reprod. Dev. 51, 53-58.

Williamson, J.R., Monck, J.R., 1990. Signal transduction mechanisms involved in hormonal Ca2+ fluxes. Environ. Health Perspect. 84, 121-136.

Zeng, H.T., Ren, Z., Guzman, L., Wang, X., Sutton-McDowall, M.L., Ritter, L.J., De Vos, M., Smitz, J., Thompson, J.G., Gilchrist, R.B., 2013. Heparin and cAMP modulators interact during pre-in vitro maturation to affect mouse and human oocyte meiosis and developmental competence. Hum. Reprod. 28, 1536-1545. 